\title{
Formação de especialistas, mestres e doutores em enfermagem: avanços e perspectivas*
}

\author{
Education of specialists, masters, and doctorates in nursing: progress and prospects \\ Formación de especialistas, maestros y doctores en enfermería: avances y perspectivas
}

\author{
Alacoque Lorenzini Erdmann ${ }^{1}$
}

\section{RESUMO}

O presente texto tece algumas considerações sobre a área da enfermagem e os avanços e perspectivas para a formação de especialistas, mestres e doutores em enfermagem. A construção de conhecimentos resulta de recursos humanos competentes no processo investigativo para um cuidado mais qualificado. Sua produção é uma importante estratégia para o fortalecimento da Enfermagem como ciência e profissão comprometida em promover melhor saúde à sociedade. A pós-graduação lato e stricto sensu em enfermagem empenha-se em formar especialistas, mestres e doutores com competência e qualificação que contribuem para o avanço da ciência e tecnologia da enfermagem brasileira. Descritores: Pesquisa em enfermagem; Especialidade; Nefrologia; Educação superior

\begin{abstract}
This paper discusses the progress and prospects of the education of specialists, masters, and doctorates in nursing. The development of knowledge results from competent human resources in the research process to promote quality nursing care. Their scientific production is an important strategy for strengthening nursing as a science and a profession committed to promoting quality health care services to society. The "strict sensu" and "lato sensu" graduate programs in nursing are committed to educate nurse specialists, masters, and doctorates with the expertise and qualifications to contribute to the advancement of Brazilian nursing science and technology.
\end{abstract}

Keywords: Nursing research; Speciality; Nephrology; Education higher

\section{RESUMEN}

El presente artículo teje algunas consideraciones sobre el área de la enfermería y los avances y perspectivas para la formación de especialistas, maestros y doctores en enfermería. La construcción de conocimientos resulta de recursos humanos competentes en el proceso investigativo para un cuidado más calificado. Su producción es una estrategia importante para el fortalecimiento de la Enfermería como ciencia y profesión comprometida en promover una mejor salud para la sociedad. El postgrado lato y stricto sensu en enfermería se empeña en formar especialistas, maestros y doctores con competencia y calificación que contribuyen al avance de la ciencia y tecnología de la enfermería brasileña.

Descriptores: Investigación en enfermería; Especialización; Nefrología; Educación superior

\footnotetext{
* Palestra apresentada no XIV Congresso Brasileiro de Enfermagem em Nefrologia e I Simpósio Internacional de Enfermagem em Nefrologia.

1 Professora Titular do Departamento de Enfermagem e Programa de Pós-Graduação em Enfermagem da Universidade Federal de Santa Catarina Florianópolis (SC), Brasil; Pesquisadora do Conselho Nacional de Desenvolvimento Científico e Tecnológico. Coordenadora da Área da Enfermagem na CAPES 2008-10.
} 


\section{BREVE INCURSÃO NA TRAJETÓRIA DA ÁREA DA ENFERMAGEM}

Inicialmente, gostaríamos de registrar nossos agradecimentos pelo convite para participar como palestrante neste importante evento da área da Enfermagem, o XIV Brazilian Congress for Nephrology Nursing presidido pela Dra. Dulce Aparecida Barbosa, para abordar questões referentes ao avanço e perspectivas da Pós-Graduação de Enfermagem brasileira na formação de especialistas, mestres e doutores. Toma-se em conta que este evento visa primordialmente a internacionalização e a formação de recursos humanos em Enfermagem em Nefrologia, para uma prática profissional da mais elevada qualidade técnico-científica, ética e humanística.

Estamos presenciando uma evolução em ritmo acelerado na formação de recursos humanos para a prática das profissões centrada no conhecimento oriundo do aprimoramento e valorização do processo investigativo.

A pesquisa na formação de especialistas, mestres e doutores em enfermagem tem importância primordial para o avanço e consolidação da ciência e tecnologia da profissão e para contribuir na melhoria da atenção/ cuidado à saúde à sociedade.

A Área da Enfermagem na Coordenação de Aperfeiçoamento de Pessoal de Nível Superior - CAPES vem crescendo em número de Programas e em cursos de doutorado, formando mestres desde a década de 1970 e de doutores desde a de 1980. Hoje, meados de 2008, conta com 32 Programas credenciados pela CAPES, sendo 14 cursos de doutorado, 29 cursos de mestrado acadêmico e dois cursos de mestrado profissional (www.capes.gov.br).

Também cresce a produção de conhecimentos científicos ou tecnológicos avançados publicados em periódicos de alto impacto, consolidando-se gradativamente nas suas especificidades e diversidades, articulada com os conhecimentos de outros setores determinantes da vida e saúde da sociedade.

Apesar deste crescimento e da implementação de políticas governamentais que promovem a pós-graduação no País, ainda convivemos com regiões do país desprovidas de programas e de doutores em Enfermagem, bem como, com poucos programas se comparados com o número de cursos de graduação em enfermagem e esta proporção também em relação às demais áreas da saúde.

Os programas de pós-graduação em nosso país são estruturados em áreas de concentração, linhas de pesquisa, projetos de pesquisa e grupos/núcleos de pesquisa cadastrados no Diretório de Pesquisa do Conselho Nacional de Desenvolvimento Científico e Tecnológico (CNPq). Esta estrutura possibilita a formação de mestres e doutores com competências investigativas em experiências práticas da profissão de enfermagem, em diferentes cenários, contemplando a diversidade de áreas de conhecimentos e práticas.

As competências no domínio do processo de construção de conhecimentos, em abrangência e especificidade de campos ou áreas de conhecimento, possibilitam trazer novos conhecimentos importantes para o avanço destas especialidades ou áreas, incluso, a especialidade de Enfermagem em Nefrologia.

Vislumbra-se um expressivo avanço nas especialidades de enfermagem, tanto em número de profissionais especialistas, como no preparo e investimento na produção de conhecimentos científicos e tecnológicos especializados. No caso da especialidade de Enfermagem em Nefrologia já conta com vários doutores em enfermagem experts nesta área de conhecimento, registro de grupos de pesquisa nesta temática, sociedade científica reconhecida e com realização de eventos internacionais com número expressivo de participantes de diferentes países e com apresentação de trabalhos de elevada qualidade científica. Esta evolução nos leva a acreditar que poderemos ter em nosso País, talvez já no curto prazo, programa de pós-graduação stricto sensu na área de Enfermagem em Nefrologia.

Assim, o presente texto objetivou tecer algumas considerações gerais sobre a área da enfermagem e os avanços e perspectivas para a formação de especialistas, mestres e doutores em enfermagem, como um processo contínuo para a consolidação da área como ciência e tecnologia, nos seus diferentes campos de conhecimento.

\section{AVANÇOS E PERSPECTIVA DA ENFERMAGEM COMO ESPECIALIDADE}

A delimitação da especificidade do campo de conhecimento e objeto de trabalho da enfermagem vem avançando e mostrando a sua natureza na sua abrangência e contornos, refletidos em ações técnico-científicas de diferentes níveis de complexidade, que implicam em ações organizativas e relacionais peculiares e complexas configurando o sistema de cuidado de enfermagem.

Reconhecemos a importância da profissão de enfermagem, suas contradições no pensar e fazer, a necessidade de suas ações, sua relevância social e capacidade resolutiva nas ações de saúde, seu domínio de conhecimentos e ainda necessidades de tecnologias avançadas. Os esforços individuais e coletivos, regionais e nacionais, a determinação em alcançar metas, as estratégias que incrementem a construção de conhecimentos relevantes e inovadores, vem sendo uma prática social desafiadora.

Reconhecemos a importância das pesquisas e da liderança dos enfermeiros neste processo, os avanços obtidos na produção de conhecimentos e no 
reconhecimento de competências político-investigativa, e os desafios enfrentados e as perspectivas promissoras ao fortalecimento e consolidação da Enfermagem brasileira, quer como profissão generalista, quer como especialista.

A formação do especialista, pós-graduação lato sensu, busca o domínio amplo ou abrangente e profundo em uma determinada área ou campo de conhecimento em enfermagem especializada, a exemplo da Enfermagem em Nefrologia.

O especialista é um profissional com potencial e capacidade para desenvolver, participar e aplicar pesquisas ou outras formas de produção de conhecimento que objetivem a qualificação da prática profissional. A melhoria da prática profissional é resultante da produção de novos saberes e fazeres. Estes podem ser frutos da pós-graduação lato sensu que desenvolve um processo de construção do conhecimento que busca integrar a teoria e a prática através da investigação e exercício da prática de cuidado com caráter investigativo.

A formação do enfermeiro especialista deve lhe promover competências ou potencial para o domínio de um campo de conhecimento específico nos seus saberes ou conhecimentos, conformados dentro de uma especialidade definida e reconhecida. Deve situar-se no domínio de novos fazeres na sua abrangência e profundidade ou complexidade própria com domínio de tecnologias avançadas, aprendidas ou experienciadas em campos de práticas de ensino de referência naquela especialidade. A estrutura curricular sustenta-se em um marco contextual e conceptual desenvolvido por docentes experts naquele campo específico de conhecimento e que adota diversidades metodológicas, com novas modalidades de ensino individuais e coletivas, presenciais e semi-presenciais, além da sistematização das experiências de trabalho e busca de novos conhecimentos centrados no aprender cuidando e pesquisando. Inclui na formação do especialista a política de fortalecimento das linhas de pesquisa pela realização de pesquisas multicêntricas ou em redes temáticas, em temáticas voltadas às prioridades de pesquisas segundo as necessidades de saúde da população de cada região já definidas pelo Ministério da Saúde. Devem ser conduzidas por pesquisadores e grupos de pesquisa de várias regiões, integrando conhecimentos e adequando-se às realidades específicas, com busca de apoio financeiro. Orientações e co-orientações devem ser integradas, estimulando a publicação conjunta entre docentes e discentes, com a produção de conhecimentos com o rigor exigido pela comunidade científica, aderentes às necessidades locais, regionais e internacionais. De outro modo, é necessário incluir a competência no gerenciar os recursos financeiros para a pesquisa, pois se entende ser indispensável dispor de recursos financeiros que viabilizem a execução dos projetos de pesquisa.
Considera-se importante e necessário um desenvolvimento ordenado da pós-graduação lato sensu e valorização da formação do especialista para avançar na qualificação profissional e no domínio do processo de construção e absorção de conhecimentos aplicados à realidade, incrementando e aperfeiçoando o nosso cuidado.

O avanço científico e tecnológico da enfermagem depende da busca de novos talentos através do incentivo à iniciação científica, do interesse e necessidade dos enfermeiros, do apoio ao trabalho de pesquisador, do apoio aos grupos de pesquisa, do fortalecimento das linhas de pesquisa, da viabilização de políticas e prioridades em pesquisa, da competência gerencial na construção de conhecimentos e da necessidade de uma prática de cuidado mais avançada científica e tecnologicamente e mais resolutiva. Ainda, depende de políticas e estratégias das instituições de saúde e órgãos de enfermagem, dos enfermeiros, das instituições de ensino e respectivos programas de pós-graduação, cursos de graduação, das sociedades científicas de enfermagem, dos grupos de pesquisa, demanda de projetos com fomento e infraestrutura para a pesquisa, demanda de candidatos interessados na formação e educação continuada em pesquisa, enfim, de uma compreensão mais ampla da importância da produção de conhecimentos para o avanço do cuidado ou das práticas em enfermagem e saúde, nos seus diversos campos específicos de conhecimentos.

\section{CONSIDERAÇÕES FINAIS}

A construção de conhecimentos resulta de recursos humanos competentes no processo investigativo para um cuidado mais qualificado. E, o desenvolvimento da pesquisa é uma importante estratégia para o fortalecimento da Enfermagem como ciência e profissão em suas generalidades e especialidades.

A produção de conhecimentos nas suas diversas especificidades ou particularidades e a liderança científica e tecnológica da Enfermagem é uma prática social desafiadora para o fortalecimento da Enfermagem como ciência e profissão na sua disciplina própria comprometida com a melhor qualidade de vida e saúde da sociedade. Os desafios serão superados na medida em que reconhecermos nossos limites e soubermos somar esforços no alcance de metas/ produtos tecnologicamente mais avançados e com maior agregação de valor, especialmente do ponto de vista científico.

A Enfermagem brasileira marca um espaço significativo nos cenários da formação cada vez mais qualificada de enfermeiros, residentes e especialistas, mestres acadêmicos e na modalidade Profissional, e doutores em Enfermagem, com exercício da prática alicerçada no processo investigativo e domínio do saber para o melhor fazer. 